
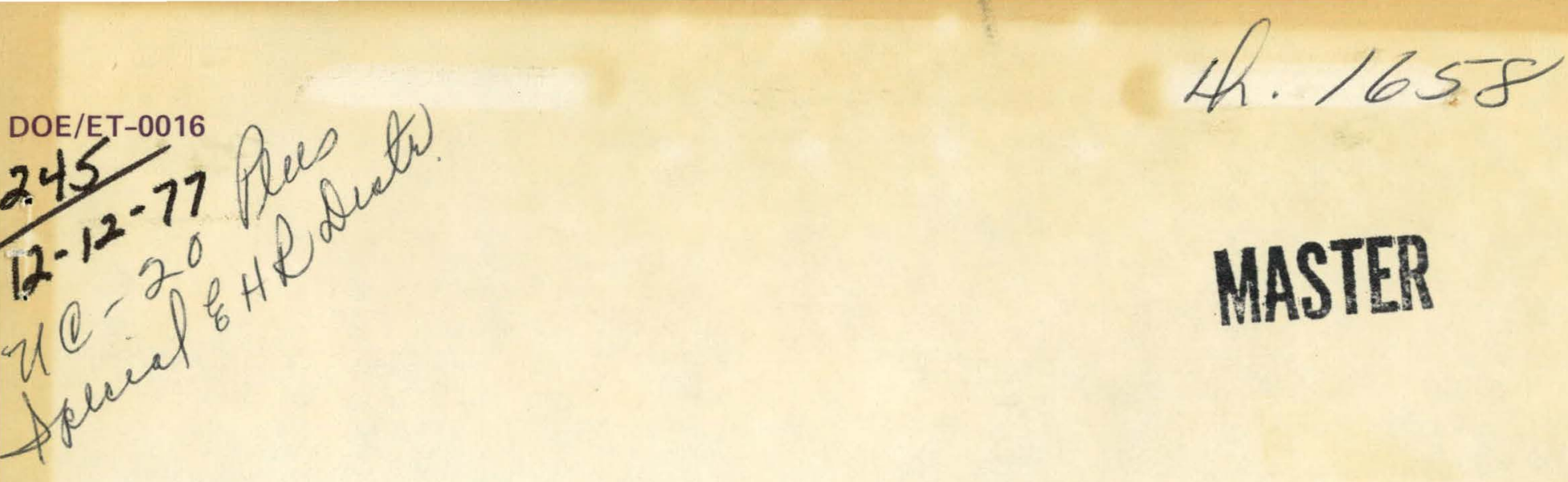

\title{
MASTER
}

\section{Superconducting Magnet Development for Tokamaks and Mirrors A Technical Assessment}

\section{U.S. Department of Energy} Division of Magnetic Fusion Energy Washington, D.C. 20545 


\section{DISCLAIMER}

This report was prepared as an account of work sponsored by an agency of the United States Government. Neither the United States Government nor any agency Thereof, nor any of their employees, makes any warranty, express or implied, or assumes any legal liability or responsibility for the accuracy, completeness, or usefulness of any information, apparatus, product, or process disclosed, or represents that its use would not infringe privately owned rights. Reference herein to any specific commercial product, process, or service by trade name, trademark, manufacturer, or otherwise does not necessarily constitute or imply its endorsement, recommendation, or favoring by the United States Government or any agency thereof. The views and opinions of authors expressed herein do not necessarily state or reflect those of the United States Government or any agency thereof. 


\section{DISCLAIMER}

Portions of this document may be illegible in electronic image products. Images are produced from the best available original document. 


\section{Superconducting Magnet Development for Tokamaks and Mirrors \\ A Technical Assessment}

Prepared By C. Laverick, R.B. Jacobs, R.W. Boom and C.D. Henning

U.S. Department of Energy

Division of Magnetic Fusion. Energy Washington, D.C. 20545

\section{November 1977}




\section{FOREWORD}

- THIS DOCUMENT WAS PRFPARED BY THE ENERGY RF.SF.ARCH AND DEVELOPMLNT ADMIPJISTRATION (ERDA) PRIUR TU I HE ACTIVATION ÖF THE DEPARTMENT OF ENERGY (DOE) BY P.L. 95-91 ON OCTOBER 1,.1977. THEREFORE, WHEREVER ERDA IS MENTIONED, IT SHOULD BE NOTED THAT ITS FUNCTIONS HAVE BEEN TRANSFERRED TO DOE.

Avarlable from:

National Technical Iuförmation Service (N'IS) U.S. Department of Commeree. 5285 Port Royal Road Springfield, Virginia 22161

Price: Printed Copy: $\quad \$ 4.50$

Microfiche: $\quad$ \$ 3.00 


\section{Preface for the Technology Assessment of the Department of Energy \\ Division of Magnetic Fusion Energy \\ Development and Technology Program}

During the past year, the Development and Technology Program has performed a series of assessments of the technologies required for a successful fusion power reactor. Technology Assessment is used here as the term to represent the evaluative process of determining (a) the requirements placed upon technology by fusion power reactor designs, (b) the fusion power reactor performance that might be achieved if future technology capabilities can be achieved, and (c) the state of the art in fusion technology compared to reactor requirements. Technology comprises that body of knowledge and experience which is needed to design, construct and operate practical fusion power reactor systems and to predict their performance and costs.

The usefuiness of Technology Assessment to the Department of Energy (DOE), Division of Magnetic Fusion Energy (DMFE), lies in its assessment of the differences between ultimate technology requirements and current technology capabilities in relation to useful and practical fusion power reactor systems. Such an assessment can be used to set research and development objectives, to allocate resources, and to measure progress toward fusion power development.

The specific objectives of the series of energy Technology Assessments are as follows:

- To identify and define technology requirements associated with developing commercial fusion power.

- To assess the current state of these technologies.

- To identify extremely difficult problems which could preclude major near-term commitments to programs strongly dependent on that technology.

- For those problems which seem amenable to practical solution, to define the character, timing and effort needed to develop the technology for application to Experimental Power Reactors, Engineering Test Reactors; and full-scale power reactors.

Technology Assessments have been performed In the fulluwing six specific areas:

Blanket and Shield

Plasma Heating, Fueling and Maintenance

Materials for Intense Radiation Environments

Special Purpose Materials for Fusion Reactors

Energy Storage and Transfer

Superconducting Magnet Development 
Although gaps in knowledge and experience in plasma physics and fusion reactor engineering subjects have been and will continue to be identified, it is not the intent of the present technology assessments to fill these gaps. Instead, the technology assessments have served their purpose when such gaps and problems are identified and quantitatively defined.

These technology assessments strive to point out known problems and highlight differences between technology requirements and technology capabilities. Since both requirements and capabilities are expected to change with time and further work, the differences should be projected only for a reasonable period into the future. In other words, a technology assessment is a snapshot in time. Further work, innovation and inventions can change the state of technology within a relatively short. period (on the order of two years) and future assessments will be needed to re-evaluate and revise the conclusinns
presented here.

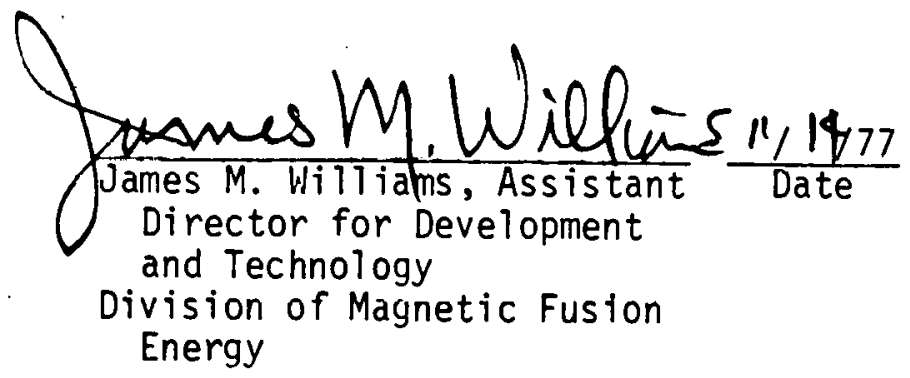




\section{SUMMARY REPORT}

SUPERCONDUCTING MAGNET DEVELOPMENT FOR TOKAMAKS AND MIRRORS -

\section{AN ASSESSMENT}

\section{April 1977}

\section{Abstract}

The role of superconducting magnets in Magnetic Fusion Energy Research and Development is assessed from a consideration of program plans and schedules, the present status of the programs and the research and development suggestions arising from recent studies and workshops.

A principal conclusion is that the large superconducting magnet systems needed for commercial magnetic fusion reactors can be constructed. However such magnets working under severe conditions, with increasingly stringent reliability, safety and cost restrictions can never be built unless experience is first gained in a number of important installations designed to prove physics and technology steps on the way to commercial power demonstration.

The immediate problem is to design a technology program in the absence of definite device needs and specifications, giving a priority weighting to the multiplicity of good, high quality development program suggestions when all proposals cannot be supported. 


\section{Preface}

Intended by the Division of Magnetic Fusion Energy, US ERDA, as the basis for a national plan for the development of superconducting magnets to be used in experimental magnetic fusion energy devices and later reactors, this assessment began as a first draft provided by ins. Shankes Laverich*, Robert B. Jacobs" and Roger W. Boom, with support and encouragement from Dr. Carl D. Henning, Branch Chief for Magnetic Systems in the Development and Technology program of the US ERDA Division of Magnetic Fusion Energy. The first draft of the assessment was discussed at a meeting of superconducting magnet experts at ERDA Headquarters on March 30 and 31, 1977 to derive the conclusions and recommendations recorded herein.

- Independent conisultarts 
At a meeting in ERDA Headquarters on March 30 and 31, 1977 and in subsequent correspondence, those listed below have discussed and drafted the conclusions and recommendations in this report.

Name

Dr. Erik Adam

Mr. Don Beard

Dr. Ron Blanken

Dr. Roger Boom

Mr. Dick Buthmann

Mr. Don Cornish

Mr. John Ferrante

Dr. Joseph File

Dr. Eric Gregory

Or. Carl Henning

Dr. George Hess, Ir.

Dr. Robert Jacobs

Dr. Clifford $K$. Jones

Dr. Charles Laverick

Mr. Martin S. Lubell

Mr. Edward 3. Lucas

Or. Jim Luton

Dr. Bruce Montgomery

Mr. John Purcell

Mr. John D. Rogers

Mr. Care Rosner

Mr. W. J. Ruhe

Mr. Wallace Withee

Mr. J. Lynn Young

\section{Organization}

AIRCO

ERDA-DMFE

ERDA-DMFE

University of Wisconsin

General Electric

Laurence Livermore Laboratory

General Electric

Princeton university

AIRCO

ERDA-DMFE

ERDA-DMFE

Robert B. Jacobs Associates, Inc.

Westinghouse

Laverick Consulting Services

Oak Ridge National Laboratory

Magnetic Corporation of America

Oak Ridge National Laboratory

Massachusetts Institute of Technology

General Atomic

Los Alamos Scientific Laboratory

Intermagnetics General Corporation

General Dynamics-Washington

General Dynamics/Convair

westinghouse 
SUMMARY REPORT

SUPERCONDUCTING MAGNET. DEVELOPMENT FOR TOKAMAKS AND MIRRORS -

AN ASSESSMENT

TABLE OF CONTENTS

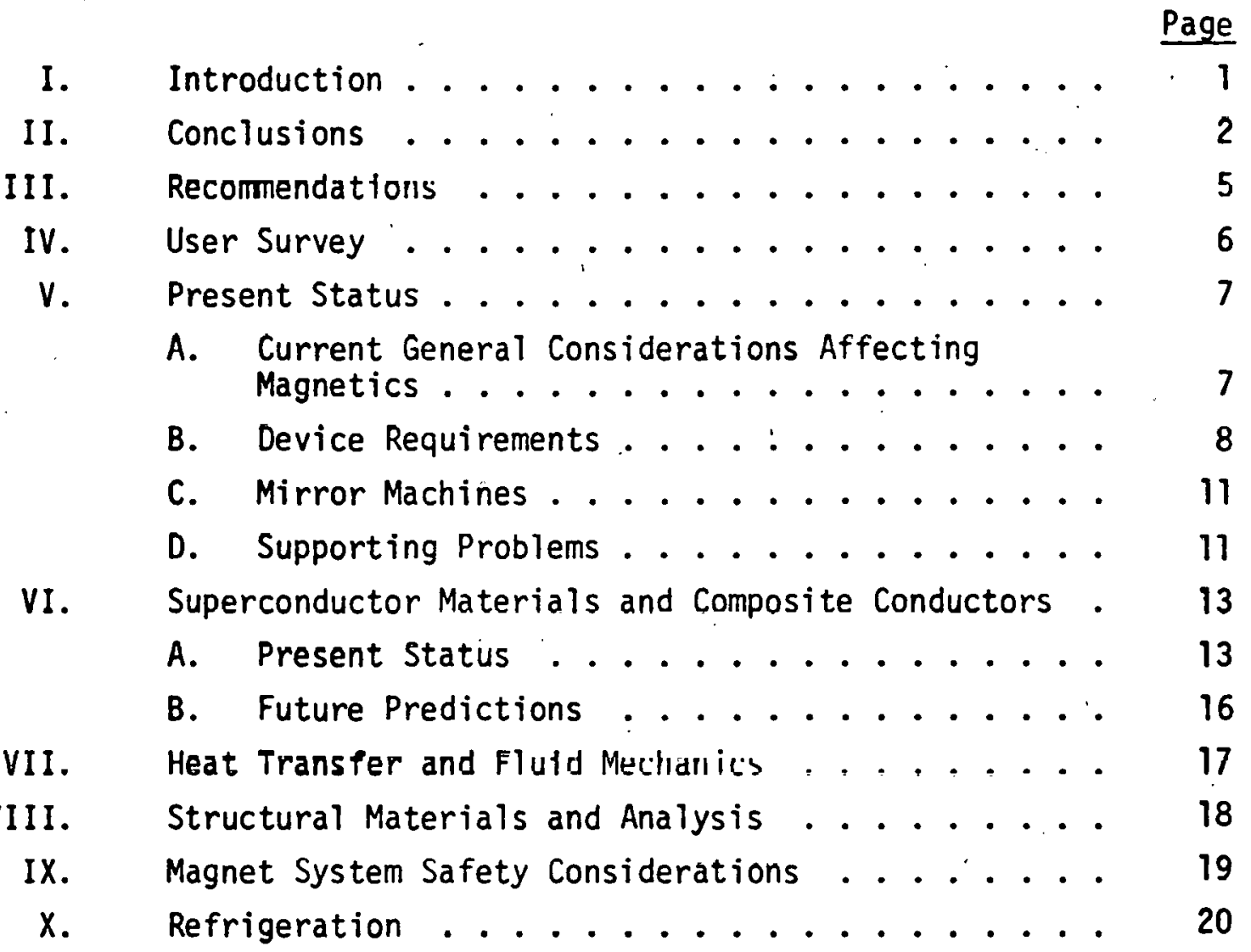




\section{Introduction}

As part of an overall ERDA-Division of Magnetic Fusion Energy . assessment to identify technological requirements associated with developing commercial fusion power by the late 1990's, to assess the current state of these technologies, and to identify problems which could preclude major near-term programs, this technology assessment of superconducting magnet development was initiated. The purposes of the national Fusion program and of the magnetics program were reviewed and compared to the present status of the superconducting magnet development Long-term program needs were considered, and problem areas of a relevant magnet program outlined. On the basis of this examination of programmatic requirements and superconducting possibilities, conclusions were drawn and recommendations made as a basis for future planning.

Since a great deal of work has been carried out on the subject of superconducting magnet development in recent years and a voluminous literature exists, an attempt was made to build on previous work and to relate the various $R \& D$ suggestions to the needs of the overall Fusion program and probable funding levels. The program plan of the Division of Magnetic Fusion Energy was used as a basis from which to work. However, energy storage and pulsed high beta systems are not included as they are the subject of a separate assessment.

A further aim of this assessment is to define the character, timing, and effort needed to develop the technology for intermediate experiments and full scale power reactors. Thus, for the magnetics program, answers to the following questions must be sought: What superconducting magnet technology requirements are associated with developing commercial fusion power by the late 1990's? What is the current state of superconducting technology with respect to the Fusion Magnetic Energy Program needs? What difficult problems might prevent the use of superconducting magnets in the experimental devices to be designed in the next ten years? 
What is the character, timing, and effort needed to use superconducting magnets in experimental power and test reactors (EPR's and ETR's) and in full scale power reactors?

II. Conclusions

Magnetics Program

a. The objectives of the magnetics program are to provide options for tokamak toroidal fields between 8 and 12 Tesla, or higher, and ohmic heating coils of $\pm 4-10$ Tesla with rise times of 1-10 seconds. Mirror magnet development should be focused on developing materials and methods to produce peak fields of 8-20 Tesla. These parameters encompass the fusion reactor requirements and can be developed with sufficient time and effort.

b. At present the magnetics program is operating at the $\$ 10 \mathrm{M} /$ year range. Assuming this funding expands as expected to $\$ 20 \mathrm{M} /$ year by 1980 , 8-10 T toroidal field coils and $8 \mathrm{~T}$ mirror coils should be available by 1982. Additional funds would be needed to develop superconducting ohmic heating coils, high field superconductors for both mirrors and tokamaks and broad based magnet technology during the same time interval.

Conduclurs

a. Magnet. designs are based on the commerctal availability of components. Decisions to produce innovative conductors must be made at least two years in advance of the decision to begin magnet construction.

b. Stable, dc, NbTi composite conductors of capacity in excess of $10 \mathrm{KA}$ can be commercially available in two years, the time required for production line development and construction. 
c. If there is a need for magnetic fields above the $16 \mathrm{~T}$ range or higher temperature operation, a new generation of superconductive materials would need to be developed.

d. Aluminum stabilized composite conductors and aluminum eddy current shields may be preferable to copper from the point of view of cost, conductivity, and weight and should be given consideration. Such advantages would be most pronounced for cryostable conductors.

\section{Coils}

a. Large magnet system projects in the planning or construction phase targeted for operation by 1992 will have to rely on $\mathrm{NbTi}$ and $\mathrm{Nb}_{3} \mathrm{Sn}$ superconductors.

b. More development of niobium-tin magnet technology is needed in order to provide for reliable extension of large coil construction experience from the 6-8 $T$ level to higher fields.

c. High current, pulsed NBTi poloidal coils may need four or five years development.

d. Engineering data on magnetic stability should be improved.

\section{Structure}

a. The optimization of structural design, reinforcement techniques and materials choices indicates that materials other than stainless steel, such as aluminum alloys and non-metallic composites are potentially' useful in reducing weight or cost. Room temperature concrete may also be used as a structural material to reduce system cost. 


\section{Refrigeration}

a. Helium refrigeration capacities required for magnetic fusion systems are larger than those available today al though some industrial compressors and heat exchangers are al ready this large. However, even these components need to be further developed for use in helium systems.

b. Helium refrigeration and control systems capable of meeting the stringent reliability requirements of reactor systems will need development.

c. Since force-cooled magnets are an attractive option, efficient supercritical helium circulation systems will need development. Preliminary studies show that low-temperature supercritical helium pumps might be more efficient than room temperature compressors with counterflow heat exchangers, but do not presently exist.

\section{Safety}

a. It is Imperative that safety considerations be integral parts of all design activities comencing with the initiation of the conceptual engineering.

\section{Radiation}

a. The impast. of radiation on superconductors, stabilizing materidls and insulation prior to their use in fusion reactors, using a radiation spectrum which simulates operating conditions should be further studied.

Helium Availability

a. Niobium-tin and niobium-titanium superconductors need to be cooled to operating temperatures in the liquid helium range. Predicted 
shortages of helium from natural gas after the turn of the century will make it necessary to turn to more expensive helium from air (at about 1000 times the dilution) unless helium can be stored for this nonwasting use.

\section{Recommendations}

1. Based on the needs of parameters and target dates, an efficient, well-focused magnetics program should have the following goals: -

$$
\begin{array}{ll}
\text { TF coils } & 8-12 \mathrm{~T} \text { or higher } \\
\text { OH coils } & \pm 4 \text { to } \pm 10 \mathrm{~T} \text { swing, } 1-10 \mathrm{sec} \\
\text { Mirror } & 8-20 \mathrm{~T}
\end{array}
$$

2. A manufacturing methods program in industry of \$1-2M/year for 2-3 years should be initiated to develop $\mathrm{Nb}_{3} \mathrm{Sn}$ for tokamaks and mirrors beyond the funds necessary for coil fabrication and testing.

3. The Compact Torus should include a $12 \mathrm{~T} \mathrm{Nb}_{3} \mathrm{Sn}$ coil.

4. DMFE should treat the development of commercial $\mathrm{NbTi}$ and $\mathrm{Nb}_{3} \mathrm{Sn}$ magnet systems as such that both can be proven in coils in a maximum of five years.

5. To support a high field option for a mid to late 1980 mirror, the LLL High Field Test Facility should be completed in 1978 with an $\mathrm{Nb}_{3} \mathrm{Sn}$ insert.

6. Sufficient funds should be dedicated to completing the Large Coil Project Test Facility with 12 T capability by 1980, consistent with the LCP coil production schedule. 
IV. User Survey

Selected experts on fusion problems were invited to respond to specific questions related to the subject of this assessment. Most respondents felt that much untapped expertise exists ready and willing to work on DMFE superconductivity projects, but that there is limited experience in total because so few large magnets and large conductors have been built. The need for industrial participation was generally recognized, but there was no generai agreement as to how that might be accomplished. It was felt that many suitable composite conductors were presently available and that many others could be made available relatively easily with adequate funding. NDTi was considered adequate for use in TF colls up to $8 \mathrm{~T}$ and, in fact, almost all present TNS and EPR designs use this material. However, $\mathrm{Nb}_{3} \mathrm{Sn}$ was not yet considered to be proven, although high fields in excess of $12 \mathrm{~T}$ might be needed and a high field option should be developed.

Two or three years was considered necessary to design, procure materials, construct, and test "large" TF coils with "available" conductors. It was thought that a more vigorous $\mathrm{Nb}_{3} \mathrm{Sn}$ development program should be supported, that more comparisons of pool cooling and forced flow cooling are needed, that cryostability criteria should be established, and that development and production of high current, high field conductor options are an absolute necessity. Accepting that the TF coil development programs could be quite ditferent, it was felt that comparisons between magnetically shielded and unshielded TF coil designs are needed.

In the case of pulsed poloidal field coils, it was felt that programs to develop such coils and their conductors needed more emphasis, since there is so little experience with such coils and conductors. The 1 to 2 second rise time used in present TNS and EPR designs has been selected from engineering and economic considerations. The plasma growth to full current could take place more slowly, based on present knowledge and 
opinions. Thus the rise time requirement for poloidal field coils (OF, $\mathrm{VH}$, etc.) is an economic or systems engineering choice not clearly necessitated by plasma physics considerations.

Respondents from industry suggested that a study group incorporating some industrial members was needed to observe ongoing work on large superconducting systems so as to be able to make informed recommendations to ERDA when comments from industry were needed. They felt that government support for production facilities and production line research and development was needed since industry cannot support such an investment burden alone and that conductor research, in particular, and other innovative industrial research and development would be best encouraged by cost plus fixed fee contracts.

\section{Present Status}

\section{A. Current General Considerations Affecting Magnetics}

The path t. commercial fusion demonstration may at least include a Prototype Experimental Power Reactor (PEPR) followed by an Experimental Power Reactor (EPR) and then a Demonstration Reactor. As the later devices increase in size, cost, complexity, severity of expected service conditions for individual subsystems, and in emphas is on increased reliability and durability, the probability of incorporating novel, new technology at each later stage in the succession decreases. Thus, at best, only eleven years remain to develop and demonstrate technology for use in an EPR and hence a demonstration reactor. The only foreseeable device which could try out superconducting technology on the necessary scale would be the PEPR. Detailed design of this device may begin in three to five years. Thus, 
the next five years should generate the basic superconducting technology to be used through to the demonstration of commercial fusion power with later developments incorporated when possible.

The current magnetics program at ORNL is focused on building toroidal field magnets of 2-1/2 $\times 3-1 / 2$ meter bore with fields between 8 and 12 Tesla. Three industrial contractors will manufacture the coils for testing in a toroidal test facility. Only a size scaling of approximately two to three will then be required to produce magnets for intermediate experiments and demonstration reactors.

Mirror reactors are currently being developed on a somewhat longer time scale than tokamaks. While near-term experiments like the Mirror Fusion Test Facility will be superconducting, they use moderate field NbTi conductors. Since higher fields are essential to mirror reactors, a $\mathrm{Nb}_{3} \mathrm{Sn}$ development program is centered at LLL with the objective of developing 12 Tesla and higher conductors and magnets.

Numerous other magnet development tasks are located at various laboratories, universities and industries. Through advisory committees, meetings, and workshops these efforts are coordinated with the main fusion reactor concepts.

\section{B. Dcrtce Requirements}

\section{Toroidal Field Coils}

a. Tokamaks. No precise definition of magnetic field or plasma radius has been specified for tokamak reactors. However, the field is expected to be between 8 and 16 Tesla and the minor plasma radius between one and two meters. An acceptable rate of rise for the ohmic heating field is roughly known to be 4-10 Tesla in 1-10 seconds. In the absence of more precise guidance, 
magnet designers have proposed and developed programs to provide options for future experiments and reactors. Niobium-titanium, because of its ductility, ready availability and ease of fabrication has been the preferred choice. However this 1 imits the operating field to a maximum of $8 \mathrm{~T}$ in pool boiling helium liquid, unless more complicated, subcooling or supercooling schemes are tried to reach $10 \mathrm{~T}$. Some upgrading of $\mathrm{NbTi}$ materials to higher fields may be possible by incorporating other metals, but this represents a new development activity. Niobium-tin, a brittle, glass-like material can probably be used up to 15 or $16 \mathrm{~T}$ but there has been a general reluctance to propose or use this material in large installations because of the probability that it may fracture during handling, conductor movement, or the inevitable strain in highly stressed, composite conductors. It should be noted that PLT operates at $9 T$, and the Princeton group has argued that the plasma containment fields necessary to guarantee operation of an economical reactor may necessitate the use of peak fields of $16 \mathrm{~T}$ in the toroidal field coils. Until the point is definitely resolved, magnet technologists and DMFE must accept the fact that there is the distinct possibility that a demonstration tokamak reactor whose conceptual design could begin in the late 1980's needs the highest peak magnetic fields which are beyond the reach of current niobium-titanium superconductors.

The toroidal field coils may be subjected to rapidly varying field changes due to their interaction with the changing vertical and poloidal fields. In some conceptual designs this pulsed field has been estimated to be as high as .6 Tesla, placing intolerably difficult constraints on TF coil design options. Fortunately system designs and coil arrangements are possible which reduce this ripple component considerably. The simplest and most reliable TF coil design would be based on dc coils. Thus, the possibility of using normal metal or superconducting shields has been advocated by some groups to reduce or eliminate the pulsed field component. Shield design options should 
therefore be included as an important, separately identified item in the magnetic activity to simplify toroidal field coil designs and conceivably reduce their estimated cost considerably.

\section{b. Ohmic Heating (OH) and Vertical (or Equilibrium)}

Field (VF) Coils. In experimental devices, where net power gain at the cheapest price is not the dominating factor, ohmic heating cuils reed not he superconducting. Howcver, there cari be no doubt that superconducting $\mathrm{OH}$ and $\mathrm{VF}$ coils will reduce input power requirements to a commercial reactor, enhance the gain and therefore net power production. While the question as to which experiment should first incorporate superconducting coils is open at the moment, the superconducting option clearly must be made available with an aggressive program sometime before the late 1980's. The coils will be large and have relatively few turns. In a typical design, the currents increase to a maximum value in 1-10 seconds during start-up at the beginning of each half hour reactor burn cycle. The need is for moderate field, very high current, alternating current superconducting coils which exhibit low ac loss and are sufficiently reliable and stable. A combination of low ac. loss and full cryogenic stability has been suggested by some groups as desirable, but may be mutually exclusive. In one design under consideration, input power to the ohmic heating coils rises to $900 \mathrm{MW}$ for a 2 GWe reactor, during a 15 second start-up. It has been suggested that about half this power be supplied from an energy storage unit which could involve superconducting components so as to reduce fluctuating demands on the electric utility systeill. If auxiliary heating is supplied during the initial discharge formation, the real limitations are probably not related to discharge physics but to the fraction of the reactor cycle that one can afford to waste in bringing the current up to maximum. This seems to imply that slower rates of rise may reduce efficiency and hence net power gain. 
c. Energy Storage. As has been mentioned previously, some form of energy storage is required for tokamak reactors to minimize the fluctuating demands on the electrical supply grid. In a 2 GWe reactor this could be of the order of $4 \mathrm{GJ}$ with about $1.5 \mathrm{GJ}$ being cycled in and out of storage. Among possible schemes, superconducting inductors and acyclic generators with superconducting coils merit consideration and the magnetics activity should be structured to develop this option.

\section{Mirror Machines}

Mirror machines require dc superconducting coils with very long charging times of the order of hours and days which may experience only slow transients due to the magnetic flux exclusion during plasma start-up. New near term experiments such as MFTF $(7.5 \mathrm{~T})$, low-field FERF $(9 \mathrm{~T})$ and the fusion-fission hybrid ( $9 T)$ were all designed with NbTi conductors. However mirror concepts which require very high magnetic fields and values from $15 \mathrm{~T}$ up to $25 \mathrm{~T}$ are currently being proposed. Structural design considerations promise to be more restrictive than the field strength limit of $\mathrm{Nb}_{3} \mathrm{Sn}$ for $15 \mathrm{~T}$ designs, and the dominant cost will be that for structure in Yin-Yang coils.

\section{Supporting Problems}

New concepts in conductor or coil design requiring long range development programs will probably demand extensions of present day technology in heat transfer and fluid mechanics. In general this type of problem is dominated by the specifics of the final design.

Structural problems in fusion reactor magnet designs are complicated by the sizes of the coils, magnitudes of the operating forces, some of which are cyclic and by the complexity and lack of 
homogeneity in magnet structures. The effects of loads on conducting shields due to varying magnetic fields and induced eddy currents are frequently overlooked and can have a devastating effect on some devices. Such effects must be given special attention in structural analysis. Thus more sophisticated analysis techniques, new structural materials, and better data handling and dissemination techniques are needed. These also should be recognized as elements of the magnetics development program.

Supercondurting magnet developments and applicatiuns in the past decade have been confined principally to the needs of research. organizations. Extrapolations of their use to commercial reactors and industry in general will. result in magnets, as components of larger installations, coming under the jurisdiction of various codes of good industrial practice and regulatory codes. It has been common experience that if such considerations are not given exposure in early conceptual designs, eventual overall program costs and schedules are considerably increased by redesign to meet such obligatory requirements. The 1977 fission reactor safety budget is around $\$ 200$ million. Clearly this important item continues to merit early and serious consideration in the magnetics program. DMFE support of the Bronkhaven National Laboratory Safety Study clearly shows that this is, in fact, recognized.

Refrigeration is a perennial discussion topic in conferences on cryogenics and applied superconductivity. In general, the manufacturers point out that the technology exists and helium refrigerators of any size and degree of reliability can be develnped when sufficient development money is made available or there is sufficient commercial volume and incentive for a device of given rating to justify the effort needed. Off the shelf laboratory size devices operated and maintained 
by small laboratory sections have frequently seemed unsatisfactory. However, large commercial plants, operated to strict industrial practice with routine maintenance schedules and permanent operating and maintenance crews have usually been reliable.

The refrigeration systems currently projected in reactor studies have higher capacities and longer term reliability requirements than have been necessary to date. The extrapolation to public utility use represents a step into the unknown and requires the initiation of planned long term engineering studies.

In conclusion, a careful study of the possibilities for applications of superconducting technology in all fields seems to show that fusion magnet requirements are unique. The DMFE program cannot rely on developments and funding from other national programs to provide significant relief for its own necessary financial and developmental commitment, with the possible exception of refrigeration development for superconducting power transmissions. Meanwhile, a well focussed, aggressive magnet technology program in these early years would enhance the chances of a successful fusion demonstration in this century and even reduce overall program costs considerably.

VI. Superconductor Materials and Composite Conductors

\section{A. Present Status}

1. Niobium-Titanium NbTi in multifilamentary form coprocessed in a copper matrix is available routinely in filament diameters as small as $10 \mu \mathrm{m}$. The material is suitable for use up to 8 Tesla at $4.2 \mathrm{~K}$ and up to 10 or even 12 Tesla at $1.8 \mathrm{~K}$ with current densities of $10^{4} \mathrm{~A} / \mathrm{cm}^{2}$ at the highest fields and $2.3 \times 10^{5} \mathrm{~A} / \mathrm{cm}^{2}$ at medium field. Within its range of usefulness $\mathrm{NbTi}$ is a highly satisfactory conductor which apparently has been optimized metallurgically. 
The composite multifilamentary conductors rely on coldwork plus heat treatment and are not easily delivered in large crosssection long lengths due to the limited size of the original extrusion billet, 30 inches $\times 12$ inches. Usually processing proceeds to smallsize, long-length composites which are later soldered, bonded, cabled, or braided with considerable high purity copper to form a cryogenically stable conductor. It is not economical to coprocess all of this copper with the smaller amount of NbTi; therefore bonding is necessary. Current bonding techniques between copper pieces and cables, braid or composite wires are comparatively crude and in an early stage of development. Pulsed coil conductors from high energy physics particle accelerator research and development programs utilize $\mathrm{NbTi}$ multifilamentary composite conductors in braids or cables but usually without much additional copper stabilizer. In some of these braids, the physical dimensions are held to a high degree of precision. Such conductors and magnets are cryogenically unstable and probably cannot be extrapolated directly to huge fusion pulsed coils. However, the work at accelerator laboratories with braid and cable coils pulsed to full field in 5 to 20 seconds is an important base of experience for future fusion pulsed poloidal coil research and development.

2. Niobium-Tin - The development of $\mathrm{Nb}_{3} \mathrm{Sn}$ has taken place over a longer period than $\mathrm{NbTi}$. Over the past 15 years diffusion forming, vapor deposition and multifilamentary "bronze" process commercial products have been available. The material was originally found to be magnetically unstable, and too strain sensitive for use in large magnets. However in the multifilamentary form the stability problem is solved and strain tolerance may be improved. Current tests under way should soon establish the limits for the use of this high field and high temperature conductor.

Niobium-tin conductors show promise for mirror machines and may become acceptable in tokamaks. However, the ideal fabrication method has not been determined nor has the proper best conductor for large magnets been developed. Final full-scale production lines for future unspecified $\mathrm{Nb}_{3} \mathrm{Sn}$ conductors will also need development. 
3. Other Conductors - Most of the other A-15 type high field conductors have all of the problems of $\mathrm{Nb}_{3} \mathrm{Sn}$ in addition to much less development time than the 15 years of intense research and development effort already spent on $\mathrm{Nb}_{3} \mathrm{Sn}$.

$V_{3}$ Ga technology has been advanced; tape and cable are available commercially. The ingenious use of copper to enhance the reaction of $V$ and $G a$ was the most important single advance to produce usable conductors. The major disadvantage is the cost, but $V_{3} G a$ carries much larger superconducting current in fields above $15 \mathrm{~T}$ than $\mathrm{Nb}_{3} \mathrm{Sn}$ does. One $\mathrm{Nb}_{3} \mathrm{Sn} / \mathrm{V}_{3} \mathrm{Ga}$ hybrid magnet has recently generated $17.5 \mathrm{~T}$ at $4.2 \mathrm{~K}$; the highest field ever achieved by a superconducting magnet. At this time there has been little effort to develop $V_{3} G a$ to the point where meaningful comparisons with $\mathrm{Nb}_{3} \mathrm{Sn}$ are possible.

$\mathrm{Nb}_{3} \mathrm{Ge}$ and $\mathrm{Nb}_{3} \mathrm{Ge}-\mathrm{Al}$ are two of the highest critical temperature materials $(23 \mathrm{~K})$ known at this time. These materials are processed by physical or chemical vapor deposition. Work with such conductors is still basic with methods to enhance critical temperature still in progress. It is difficult to estimate the time or effort required to bring these conductors into practical use for large fusion magnets.

The general progress with a 11 of the A-15 conductors is most noted for systems which do not naturally form stochiometrically. It appears that many such conductors can be brought close to stochiometric by substantial oxygen (1 4\%) addition during formation resulting in higher critical temperature. It is speculated that $\mathrm{Nb}_{3} \mathrm{Si}$ may thus be developed up to $\overline{\mathrm{T}}_{\mathrm{c}}$ $240 \mathrm{~K}$.

Another class of conductors of the C-15 structure, lavesphase compounds, has received some attention. The critical temperature is not especially high for VHf-VZr or VHf-NbHf pseudo-binary alloys $(10.5 \mathrm{~K}$ ) but the critical field at $4.2 K$ is 26 Tesla. An exciting possibility is 
that mechanically the material may be much less brittle than the A-15 structures, $\mathrm{Nb}_{3} \mathrm{Sn}, \mathrm{Nb}_{3} \mathrm{Al}, \mathrm{Nb}_{3} \mathrm{Ge}, \mathrm{V}_{3} \mathrm{Ga}, \mathrm{V}_{3} \mathrm{Si}$, etc. This was inferred from hardness tests but further substantiation is necessary.

\section{B. Future Predictions}

1. Near-Term NbTi - High current, up to 100,000 A, composite cryogenically stable conductors of NbTi plus $\mathrm{Cu}$ can be delivered within two years, depending only on produrtian line construction and conductor uptimization and qualification tests.

Also it may be possible to develop high current, up to 100,000 A, composite pulsed conductors capable of near cryogenically stable operation after 10 second pulses to full current and field in about four years. If one second pulses are needed, the level of risk must be increased because the dc stability may be reduced. Fortunately, one second $\mathrm{OH}$ coil pulses may only be needed for near-term experiments where some element of risk can be tolerated or copper colls can be used:

\section{Intermediate Termil - $\mathrm{Nb}_{3} \mathrm{Sn}$ multifilamentary cryogenically} stable high current, up to $100,000 \mathrm{~A}$, conductors could be developed, qualified and delivered in large quantities in about five years if adequate tinancial support is available.

However, it would take a crash program to optimize conductors from several options, confirm with substantial magnet construction and test, and then construct conductor production lines. The addition of extra copper may possibly present problems other than those met for NbTi.

3. Long Term - Fifteen years has not been sufficient for the develicpment of $\mathrm{Nb}_{3} \mathrm{Sn}$. Thus most new conductors. will require long term development. Large conductors of $\mathrm{NbTi}$ are still to be developed and the 


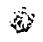

strain limitations of $\mathrm{Nb}_{3} \mathrm{Sn}$ are still to be worked out. Totally adequate conductor production lines are yet to be built because of limited usage.

$V_{3}$ Ga conductors, if needed, should be very simple to develop since the ir production requires the same technology as $\mathrm{Nb}_{3} \mathrm{Sn}$ multifilamentary conductors. However interest and funding in this more expensive conductor precludes its near term development. $\mathrm{Nb}_{3} \mathrm{Ge}$, $\mathrm{Nb}_{3}(\mathrm{Ge}-\mathrm{Al})$ and $\mathrm{VHF}-\mathrm{VZr}$ are probably closer to 15 years from any large scale use. High $\mathrm{T}_{\mathrm{c}}, \mathrm{Nb}_{3} \mathrm{Si}$ is most likely 20 years away from use. Long lead times could be shortened with better than expected financing.

However it should be remembered that only NbTi is usefur until a very major commitment to another conductor is made. The ordinary sequence is that $T_{C}$ is optimized first, then $J_{C}$ is optimized through several production schemes, then all sorts of bonding to copper or aluminum matrices are tried, and finally one of several conductor fabrication methods is chosen. After that a series of model magnet qualification tests are needed and finally a conductor production line is built. Without funding, long range possibilities always remain long range.

VII. Heat Transfer and Fluid Mechanics

In the design of superconducting maqnet systems, heat transfer and fluid mechanics problems are encountered in several locations: the magnet windings (both in the conductors themselves and in the vicinity of the conductors), the refrigeration system, the refrigerant transfer and handling systems, structural systems supporting low temperature components, relief and venting systems, insulation systems, etc. Resolution of many of these design problems is well within existing technology; resolution of the others will require research and development activities, some long-range and some short-range. 
It is important to note that the heat transfer and fluid mechanical characteristics of these systems are extremely sensitive to physical and geometrical details. Therefore, the empirical, and probably theoretical, activities pursued to obtain required design information should be narrowly-scoped and must be strongly influenced by specific design concepts.

The long-range heat transfer and fluid mechanical problems encountered in refrigerators are recognized, but there is no urgent need to initiate immediate engineering studies in this area. Shorterrange (up to three years duration) engineering activities required for the resolution of the various heat transfer and fluid mechanical problems can be handled within the frameworks of the specific reactor development programs. This is an effective, well-proven approach for the resolution of these kinds of technological problems. It will be acceptable for the MFE program because of the time intervals allotted to the conceptual design and preliminary design activities in the ERDA/DMFE Program Plans: three years for conceptual design and one to two years for prel iminary design.

\section{Structural Materials and Analys is}

While some feel that present structural analysis techniques are adequate to enable them to design reliable magnet system structures, others feel that effort should be devoted to the development of more sophisticated techniques; the development of new structural materials; the codification and standardization of testing procedures; and the organization and presentation of data so that it is readily available and can be utilized efficiently. The nature of many of the requirements (e.g., the development of new materials, and the development of better analytical models) is such that long-range research will be needed, and an active program should be continuing. 
Homogenization techniques and coupled analysis techniques to account for thermal, electro-magnetic, and structural interaction in structural analysis could be improved. The data base for material properties should be extended as needed. Fracture mechanics methods could be adapted to predict failure of metallic components and methodology could be developed to describe organic material fracture behavior.

An ongoing program to survey and improve the understanding of materials properties at low temperatures and to extend engineering design data is under way at NBS-Boulder with ERDA support. This program and continuing work in other organizations over the next few years will increase the sophistication and range of available options in low temperature structural design.

IX. Magnet System Safety Considerations

We must accept regulatory safety requirements and programs as a fact of life. The integrity and safety of superconducting magnet systems constructed during the last decade has been left to the discretion of individual designers and their organizations, as one would expect. Extensions of the technology to very much larger and more expensive coils for nuclear fusion reactors, where the coils enclose fusing plasmas, radioactive blankets and significant quantities of tritium, makes it essential to consider safety problems and their impact on conductor coil and system design.

- Safety research and analysis in the United States is a mature and essential component of fission reactor program development with a 1977 budget of around $\$ 200$ million. In nuclear fusion reactors, the very large coils enclose a mixture of radioactive fusion and fission products whose escape to the outside world would not be tolerated, even under the most unlikely accident or sabotage conditions. This national concern for reactor safety does not leave room for an independent individual approach 
to each system or sub-system problem. Safety decisions rest on explicit, well developed disciplines from which subjective judgements have been reduced to the absolute minimum.

The approach of accepting a finished design then re-designing to meet mandatory safety standards and requirements would result in very long program delays and considerable expense. This is confirmed by those involved in safety and design development for fission reactors. The most expedient and economic programmatic method is to incorporate safety requirements as the conceptual design evolves.

Both the electrical and structural aspects of magnet safety need to be considered. Principal items include the types of safety system that may be needed for fusion magnets, structural analysis for selected fault conditions, heat transfer analyses, electrical breakdown possibilities, energy removal techniques, stability criteria, magnet lead design and the impact of power supply shutdown on system operation. In general, magnet disruption accidents seem unlikely if appropriate safety systems are installed.

\section{x. Refrigeration}

The provision of refrigcrators, of the capacities dild reliabililies required for superconducting public utility applications, will require long-range development. Iterative studies required to ascertain refrigeration requirements for the various models of tokamak and mirror machines, and to delineate the characteristics of the necessary refrigeration systems, should begin as soon as possible.

The deficiencies in refrigerator technology stem primarily from the high system reliabilities required of commercial power plants, and from the very large refrigerator capacities that are anticipated. The iatter require the development and evaluation of components with capacities that are orders of magnitude greater than those found in present helium refrigerator technology. 
Estimates of the 4 to $5 \mathrm{~K}$ refrigeration required for EPR superconducting magnets run from about $100 \mathrm{KW}$ to more than $1200 \mathrm{KW}$. Extrapolation to DEMO and Commercial systems might lead to requirements one to two orders of magnitude greater. Existing systems generally have capacities of $1 \mathrm{~kW}$ and less with one system of $1.5 \mathrm{KW}$ at $4.2 \mathrm{~K}$, one of $4 \mathrm{KW}$ at $10 \mathrm{~K}$, and one of $5 \mathrm{KW}$ at 14-17 K. Additionally, some current plans and design studies for Magnetic Fusion Reactors include very high capacity cryopumping systems operating in the 4-5 $\mathrm{K}$ range; these refrigeration requirements increase the needed refrigerator capacities even more. None of the existing refrigerators has reliability characteristics that satisfy public utility requirements.

The current ERDA/DMFE long-range program plans allow ample time for needed refrigerator development if this activity is started soon. Initial paper studies could determine the ranges of refrigeration characteristics needed to satisfy the reactor (not merely the magnet) requirements, and determine the nature of the component and system development program at a modest level of funding.

The refrigeration systems required for the PEPR/ITR and EPR reactors probably do not require reliabilities that are difficult to achieve; the levels of reliability achieved on large air separation plants will probably be adequate. Of the primary refrigerator components (turbines, compressors, heat exchangers, and purifiers), compressors may be the only ones that will require basic innovation and substantial development. Scale-ups and multi-unit installation may generally take care of the other components.

Many of the components that determine reliability are not functions of refrigeration capacity; examples of those are control and instrumentation, operating and maintenence procedures, and mechanical and electrical switching equipment. The improvement of existing concepts, systems, and components, can be carried on at low levels of effort over rather long time periods. 